\title{
Phase Segregation during Processing of Semi-Solid Slurry by Rheocasting Method SEED
}

Barbora Bryksí Stunová1, Vlastimil Bryksî́

${ }^{1}$ CTU in Prague, Faculty of Mechanical engineering, Dept. of Manufacturing Technology, Technická 4, 16604 Prague, Czech Republic. E-mail: barbora.stunova@fs.cvut.cz

${ }^{2}$ Kovolis Hedvikov, a.s., Hedvikov 1, 538 43, Třemošnice, Czech Republic. E-mail: v.bryksi@ kovolis-hedvikov.cz

The paper describes specific phenomena of semi-solid casting process, especially rheo-casting method SEED, which uses mechanical swirling for reaching proper structure in semi-solid state. The eutectic segregation during processing of semi-solid slurry can cause specific casting defects. Heat treated alloy AlSi7Mg0.3 was applied for producing castings. For observing structure, metallographic observation by light and SEM microscopy was used as well as spectral analysis.

Keywords: Semi-Solid, Rheo-Casting, Phase Segregation, Aluminium Alloys, Casting Defects

\section{Anknowledgment}

This work was supported by the project No SGS 13/187/OHK2/3T/12.

\section{References}

[1] DA SILVA M., LEMIEUX A., CHEN X.G. (2009). Characterization of semi-solid slurry using a novel "RheoCharacterizer" apparatus. In: Journal Of Materials Processing Technology, 209, pp. 5892-5901.

Foundry Product SEED. (2015) Retrieved April 102015 from: http://www.stas.com/images/stories/Document/SEED/seed_brochure.pdf

[2] LASHKARI O., AJERSCH F., CHARETTE A., CHEN X.G. (2008). Microstructure and rheological behavior of hypereutectic semi-solid Al-Si alloy under low shear rates compression test. In: Materials Science and Engineering A., pp. 377-382.

[3] LEMIEUX A., LANGLAIS D., BOUCHARD X., CHEN X.G. (2010). Effect of Si, Cu and Fe on mechanical properties of cast semi-solid 206 alloys. In: Transactions of Nonferrous Metals Society of China, 20, pp. 15551560.

[4] TEBIB M. AJERSCH F. GRANT CHEN X. (2012). Rheological Properties and Mocrostructure of Hypereutectic Semi-solid Al-Si-Mg Alloys Using Rheo-casting Route. In: S2P 2012 - 12th International Conference on SemiSolid Processing of Alloys and Composites, pp. 1 - 7.

[5] Semi-Solid Thixoforming: Part two. In: Total Materia. (2013) Received August 272015 from http://www.keytometals.com/freedemo/page.aspx?ID=CheckArticle\&site=ktn\&LN=EN\&NM=323. 